\title{
Shortcomings of protocols of drug trials in relation to sponsorship as identified by Research Ethics Committees: analysis of comments raised during ethical review
}

\author{
Marlies van Lent ${ }^{1 *}$, Gerard A Rongen ${ }^{2,3}$ and Henk J Out ${ }^{1,4}$
}

\begin{abstract}
Background: Submission of study protocols to research ethics committees (RECS) constitutes one of the earliest stages at which planned trials are documented in detail. Previous studies have investigated the amendments requested from researchers by RECs, but the type of issues raised during REC review have not been compared by sponsor type. The objective of this study was to identify recurring shortcomings in protocols of drug trials based on REC comments and to assess whether these were more common among industry-sponsored or non-industry trials.

Methods: Retrospective analysis of 226 protocols of drug trials approved in 2010-2011 by three RECs affiliated to academic medical centres in The Netherlands. For each protocol, information on sponsorship, number of participating centres, participating countries, study phase, registration status of the study drug, and type and number of subjects was retrieved. REC comments were extracted from decision letters sent to investigators after review and were classified using a predefined checklist that was based on legislation and guidelines on clinical drug research and previous literature.
\end{abstract}

Results: Most protocols received comments regarding participant information and consent forms $(n=182,80.5 \%)$, methodology and statistical analyses $(n=160,70.8 \%)$, and supporting documentation, including trial agreements and certificates of insurance $(n=154,68.1 \%)$. Of the submitted protocols, $122(54.0 \%)$ were non-industry and 104 (46.0\%) were industry-sponsored trials. Non-industry trials more often received comments on subject selection $(n=44,36.1 \%)$ than industry-sponsored trials ( $n=18,17.3 \% ; R R, 1.58 ; 95 \% C l, 1.01$ to 2.47), and on methodology and statistical analyses ( $n=95,77.9 \%$ versus $n=65,62.5 \%$, respectively; $R R, 1.18 ; 95 \% C l, 1.01$ to 1.37). Non-industry trials less often received comments on supporting documentation $(n=72,59.0 \%)$ than industry-sponsored trials ( $n=82,78.8 \% ; \mathrm{RR}, 0.83 ; 95 \% \mathrm{Cl}, 0.72$ to 0.95$)$.

Conclusions: RECs identified important ethical and methodological shortcomings in protocols of both industry-sponsored and non-industry drug trials. Investigators, especially of non-industry trials, should better prepare their research protocols in order to facilitate the ethical review process.

Keywords: Research ethics committees, Ethical review, Research protocols, Drug trials, Sponsorship, Pharmaceutical industry, Shortcomings

\footnotetext{
* Correspondence: Marlies.vanLent@radboudumc.nl

'Clinical Research Centre Nijmegen, Department of Pharmacology -

Toxicology, Radboud University Medical Center, Nijmegen, The Netherlands

Full list of author information is available at the end of the article
} 


\section{Background}

Before new drugs can enter the market, they are extensively investigated in clinical trials. Also after registration, clinical drug research is important to improve our knowledge on safe and effective use of drugs [1]. In addition, drugs are frequently used as tools to investigate physiology and pathophysiology in humans in vivo. Prior to the recruitment of trial participants, research protocols need to be evaluated by research ethics committees (RECs) to assess whether all scientific, ethical, and legal requirements for conducting drug research with human subjects are met [2,3]. Studies may raise questions of informed consent, adequate subject selection, scientific validity, acceptable risk-benefit ratios, and the value of the research to society in relation to the burdens to participants [4].

Submission of study protocols to RECs constitutes one of the earliest stages at which planned trials are documented in detail. Prior studies on ethical review of protocols involving human subjects have investigated the type of amendments and clarifications requested from researchers by RECs. For many protocols, some type of amendment was needed before approval [5-7]. RECs frequently commented on inadequacies in informed consent forms, possible risks to participants, methodological and statistical issues in protocols, and missing or incorrect supporting documentation [5-10]. However, several studies on REC review included small numbers of protocols $[5,9,10]$, or focused on protocols submitted to single RECs so resulting findings may be specific to the committee studied [5,6]. In addition, although the issues raised by RECs may depend on the intervention tested, previous studies have included protocols regardless of the type of intervention $[5-8,10]$.

The type and extent of shortcomings detected by RECs may also be related to sponsorship of trials. Pharmaceutical companies generally have larger budgets and a better research infrastructure compared to non-profit organizations, which could lead to higher protocol quality. However, it has also been suggested that the pharmaceutical industry's pursuit of profit and favourable study results may have negative effects on research quality $[11,12]$. Studies based on published trials have indicated that methodological quality is comparable for industry-sponsored and non-industry trials [12-14]. However, for a cohort of trials submitted to a Dutch REC, it was shown that non-industry trials have more problems in recruiting the required number of subjects than studies initiated by pharmaceutical companies [15]. This was confirmed in a study with protocols approved by RECs in Switzerland, Germany, and Canada indicating that industry-sponsorship was associated with lower rates of trial discontinuation due to poor recruitment [16]. The shortcomings of protocols that are identified during REC review have not been compared by sponsor type though.
The objective of this explorative study was to identify recurring shortcomings in protocols of drug trials and to assess whether these are more common among industrysponsored or non-industry trials. Protocols submitted to three RECs affiliated to academic medical centres in The Netherlands were included and REC decision letters sent to researchers after review were accessed. REC comments were extracted and classified using a predefined checklist that was based on legislation and guidelines on clinical drug research and previous literature. It was examined whether there was a relationship between the occurrence of certain types of comments and industry sponsorship.

\section{Methods}

\section{Selection of RECs and protocols}

All eight RECs affiliated to academic medical centres in The Netherlands were asked to provide access to submitted protocols and their correspondence with investigators. These eight committees together review $70 \%$ of all medical research with human subjects conducted in The Netherlands [17]. RECs located in Nijmegen (CMO), Amsterdam (METc VUmc) and Leiden (CME) agreed to participate. Other committees did not participate due to logistical or confidentiality issues. All protocols approved in 2010-2011 were included, if they were classified as trials with medicinal products.

\section{Extraction of trial characteristics}

For each protocol, information was retrieved on sponsor type, number of participating centres, participating countries, study phase, type of subjects, anticipated number of subjects, and whether the study drug was registered in The Netherlands. Data were extracted from a standardized form used in The Netherlands to prospectively document characteristics of planned trials (ABR form). Trials were classified as non-industry or industry-sponsored trials. For industry-sponsored trials, a pharmaceutical company was explicitly reported as the study sponsor in the ABR form. We verified whether the company indeed had the overall responsibility for the conduct of the trial using the trial protocol, clinical trial agreement and correspondence between the REC and investigators. Nonindustry trials were investigator-initiated studies for which no associations with pharmaceutical companies were reported, or investigator-initiated studies that received study medication or financial support from manufacturers which did not have any responsibility for the content of the protocol.

\section{Extraction and classification of REC comments}

For the classification of REC comments, a comprehensive checklist was composed prior to accessing REC decision letters (Table 1). The content of this checklist was based on national and international legislation and guidelines 
Table 1 Classification checklist for REC review of protocols of drug trials

\begin{tabular}{l} 
Review criteria \\
\hline 1. Proportionality \\
$\begin{array}{l}\text { 2. Minimisation of risks \& } \\
\text { burdens }\end{array}$
\end{tabular}
burdens

3. Privacy \& confidentiality

4. Patient safety

5. Recruitment process

6. Information sheet \& consent form

7. Subject selection

8. Protection vulnerable subjects 9. Methodology \& statistical
analysis

10. Product information

11. Supporting documentation

12. Facilities \& research staff

13. Financial aspects

\section{Definition}

Risks and burdens to subjects are reasonable in relation to anticipated benefits

Trial leads to important medical knowledge and/or considerable health benefits

Participation does not involve unacceptable/disproportionate risks or burdens to subjects, use of placebo in trial is ethically justified

Risks and burdens to subjects are minimized

Research question cannot be answered without inclusion of human subjects

Research question cannot be answered by more simple or less riskful/burdensome research

Adequate provisions are made to protect privacy of subjects and maintain confidentiality of data and body tissues Trial data and body tissues are adequately coded, stored and protected, with restricted access for third parties

Adequate provisions are made to ensure safety of subjects during the trial

Collected data are adequately monitored and (if necessary) a Data and Safety Monitoring Board (DSMB) is installed Individual and group level stopping criteria are adequate

Recruitment methods and payments to subjects are acceptable

Investigator has access to population that allows recruitment of required number of subjects

Subjects are given adequate opportunity and time to ask questions and decide about participation

Subject information sheet \& consent form contain all required elements

The length, structure and language use of the information sheet \& consent form will allow subjects to understand them correctly

Subject selection is appropriate to answer the research question

Inclusion and exclusion criteria are adequate and complete, equity in subject selection

When vulnerable subjects are included, there are additional safeguards to protect their rights and well-being

No vulnerable subjects are included, unless they may benefit themselves from participation or trial cannot be conducted without them

Trial design/methodology is appropriate and properly motivated in protocol

Selected primary \& secondary endpoints and dosage regimen are appropriate

Sample size calculations and planned statistical analyses are adequate

Product information on the medicinal product(s) used in the study is adequate

Investigator's Brochure (IB) and Investigational Medicinal Product Dossier (IMPD)/ Summary of Product Characteristics (SPC) are acceptable

Other documents submitted as part of the research proposal are acceptable

Data in ABR form are complete and correct and the Clinical Trial Agreement is in accord with Dutch regulations

Required insurances for medical research with human subjects are arranged

Research staff members are experienced and qualified to conduct trial procedures

Investigator has adequate facilities to conduct the trial

All costs incurring during the trial are adequately covered

Compensation fees paid to investigators or institutions are proportional to the size, nature, and purpose of the trial Conditions (e.g. financial interests) leading to conflicts of interest are prevented

on the conduct of drug research with human subjects, and previous literature on this topic $[2-4,18-21]$. This resulted in a checklist consisting of thirteen review criteria, that need to be considered by RECs to assess whether all scientific, ethical, and legal requirements for drug trials are met. For each trial, the issues raised by RECs were extracted from REC decision letters that were sent to investigators after protocol review. As these comments were not described in a standardized manner in REC letters, all data were first fully transcribed and subsequently categorized using the classification checklist. During the extraction of REC comments, there was no blinding for sponsorship as this was unfeasible due to logistical reasons. In this explorative study, the categorization of comments was performed by one author. Submitted protocols could be discussed by RECs at several occasions before receiving approval. All correspondence between RECs and investigators prior to approval was included in this study. 
Furthermore, the number of days between protocol submission and final REC approval was determined, which consisted of time attributable to RECs and time used by researchers to respond to comments.

\section{Statistical analysis}

The association between sponsor type and the number of trials that received comments after REC review was analyzed using generalized linear models (log-binomial) for each of the thirteen review criteria. We controlled for the REC that reviewed the protocol by including both sponsor type and REC as predictors in the model, and tested for interaction between sponsor type and REC. Associations between sponsor type and the number of trials that received comments were estimated with relative risks (RRs) and 95\% confidence intervals (CIs). The total time between protocol submission and REC approval was compared by sponsor type and REC using a two-way ANOVA. We tested for interaction between sponsor type and REC. As time to approval was positively skewed, data were Ln-transformed before testing for differences between groups. $\mathrm{P}<.05$ was considered statistically significant. Because of the explorative character of this study, P-values were not adjusted for multiple comparisons. Statistical analyses were performed using SPSS software (version 20; Chicago, Illinois).

\section{Ethics}

To assure confidentiality of information in submitted protocols and correspondence between RECs and investigators, confidentiality agreements were signed before gaining access to the data. As standard REC procedures were unchanged, investigators were not informed about this study. Formal REC approval was not required for this study as no human subjects were involved.

\section{Results}

In 2010 and 2011, 226 protocols of drug trials were approved by three Dutch RECs (Nijmegen, $\mathrm{n}=74$; Amsterdam, $\mathrm{n}=76$; Leiden, $\mathrm{n}=76$ ) (Table 2). In 2010, $123(54.4 \%)$ protocols were approved, compared to 103 (45.6\%) in 2011. Of the submitted trials, 104 (46.0\%) were sponsored by the pharmaceutical industry and 122 (54.0\%) were non-industry trials, of which 31 were financially or materially supported by a for-profit organisation (13.7\% of the total number of trials).

Most studies were multicentre trials $(\mathrm{n}=126 ; 55.8 \%)$ and were mostly conducted in The Netherlands only $(\mathrm{n}=131 ; 58.0 \%)$ (Table 2). 31 of the 126 multicentre studies $(24.6 \%)$ were performed in The Netherlands only, whereas 95 (75.4\%) were multinational multicentre studies. Trials were categorized as phase $1(n=21 ; 9.3 \%)$, phase $2(n=62 ; 27.4 \%)$, phase $3(n=62 ; 27.4 \%)$, phase $4(\mathrm{n}=17 ; 7.5 \%)$, or other trials involving medicinal
Table 2 Characteristics of drug trials approved in 2010-2011

\begin{tabular}{ll}
\hline & Protocols \\
\hline REC & $226(100)$ \\
Nijmegen & \\
Amsterdam & $74(32.7)$ \\
Leiden & $76(33.6)$ \\
Year of approval & $76(33.6)$ \\
2010 & \\
2011 & $123(54.4)$ \\
Sponsor type & $103(45.6)$ \\
Non-industry & \\
Non-industry, supported by industry & $91(40.3)$ \\
Industry-sponsored & $31(13.7)$ \\
\hline
\end{tabular}

Number of centres

Single centre 100 (44.2)

Multicentre $126(55.8)$

NL only or international trial

NL trial $131(58.0)$

International trial 95 (42.0)

Phase

Phase $1 \quad 21(9.3)$

Phase $2 \quad 62(27.4)$

$\begin{array}{ll}\text { Phase } 3 & 62(27.4)\end{array}$

Phase $4 \quad 17(7.5)$

Other 64 (28.3)

Study drug registered in NL

Yes, for the same indication/dosage as studied in $\quad 50$ (22.1) protocol

Yes, for different indication/dosage than studied in $\quad 74$ (32.7) protocol

No

$79(35.0)$

Not reported whether drug was registered in NL

$23(10.2)$

Type of subjects

Adult subjects capable of giving informed consent 208 (92.0)

Adult subjects not capable of giving informed consent 7 (3.1) and/or minors $<18$ years

Adult subjects capable of giving informed consent and 11 (4.9) adults not capable of giving informed consent or minors $<18$ years

Anticipated number of subjects, median (IQR)

Number of subjects (total)

$59(24-240)$

Number of subjects (NL trials)

$34(20-60)$

Number of subjects (international trials)

$300(120-800)$

products $(\mathrm{n}=64 ; 28.3 \%)$. In 50 trials $(22.1 \%)$, a drug registered in The Netherlands for the same indication/dosage as studied in the trial protocol was used, while 74 (32.7\%) 
used drugs that were registered for a different indication/ dosage than studied in the protocol, and 79 (35.0\%) used drugs that were not registered in the Netherlands. For 23 trials $(10.2 \%)$, it was not reported whether the study drug was registered. Most trials recruited adult subjects capable of giving informed consent $(n=208$; 92.0\%), while $7(3.1 \%)$ trials included adult subjects not capable of giving informed consent and/or minors $<18$ years, and 11 (4.9\%) included both types of subjects. The median number of subjects per trial was 59 (interquartile range (IQR), 24-240). The median number of subjects in trials conducted in The Netherlands only was 34 (IQR, 20-60), compared to 300 (IQR, 120-800) in multinational trials.

In Table 3, random examples of comments raised during REC review are presented to illustrate each type of shortcoming. Table 4 shows the number of trials that received comments for each of the review criteria. Most trials received comments on the subject information sheet and consent form $(\mathrm{n}=182,80.5 \%)$, methodology and planned statistical analyses $(\mathrm{n}=160,70.8 \%)$, and supporting documentation, including clinical trial agreements and certificates of insurance ( $\mathrm{n}=154,68.1 \%)$. In contrast, RECs rarely commented on the minimization of risks and burdens to subjects $(\mathrm{n}=26,11.5 \%)$, financial aspects $(\mathrm{n}=39,17.3 \%)$, and the protection of vulnerable subjects $(\mathrm{n}=9,4.0 \%)$.

Non-industry trials more often received comments on subject selection $(\mathrm{n}=44,36.1 \%)$ than industry-sponsored trials $(\mathrm{n}=18,17.3 \%$; RR, $1.58 ; 95 \%$ CI, 1.01 to 2.47$)$ (Table 4). More non-industry trials received comments on methodology and statistical analyses $(n=95,77.9 \%)$ compared to industry-sponsored trials $(n=65,62.5 \%$; $R$, $1.18 ; 95 \% \mathrm{CI}, 1.01$ to 1.37$)$. In contrast, non-industry trials less often received comments on supporting documentation $(\mathrm{n}=72,59.0 \%)$ than industry-sponsored trials ( $\mathrm{n}=82,78.8 \%$; RR, $0.83 ; 95 \% \mathrm{CI}, 0.72$ to 0.95 ). There was a non-significant trend indicating that non-industry trials more often received comments related to facilities and research staff $(\mathrm{n}=39,32.0 \%)$ compared to industrysponsored trials ( $\mathrm{n}=18,17.3 \%$; RR, 1.60; $95 \% \mathrm{CI}, 0.98$ to 2.60). The proportion of trials that received comments was comparable between RECs for protection of vulnerable subjects and product information. For the other review criteria, the proportion of trials with comments was significantly different between RECs (data not shown). For product information and supporting documentation, the interaction between sponsor type and REC was $\mathrm{p}<.05$. However, RRs for the association between sponsorship and these review criteria were comparable for the individual RECs and the interaction was considered not relevant with regard to the effect of sponsorship.

The median time to protocol approval was 112 days (IQR, 78-163) (Table 5). Time to approval was not significantly different between industry-sponsored (119 days; IQR, 84-169) and non-industry trials (101 days; IQR, $75-158, \mathrm{p}=.298$ ). Time to approval was longer for protocols submitted in Nijmegen (148 days; IQR, 89-203) than for those submitted in Amsterdam (113 days; IQR 87-150) or Leiden (91 days; IQR, 65-127, overall $\mathrm{p}=.000$ ). There was no interaction between sponsor type and REC regarding time to approval.

\section{Discussion}

In this study, recurring shortcomings in protocols of drug trials were identified based on REC comments and it was assessed whether these were more common among industry-sponsored or non-industry trials. Most protocols received comments regarding informed consent forms, methodology and planned statistical analyses, and supporting documentation including clinical trial agreements and certificates of insurance. This corresponds to findings of previous studies on the issues raised by RECs $[5-7,9]$. In addition, a recent evaluation of the Dutch law on medical research with human subjects also indicated that RECs give a lot of attention to improvement of participant information [22]. RECs rarely addressed the minimization of risks and burdens to subjects, financial aspects, and the protection of vulnerable subjects. The last finding is hardly surprising, as $90 \%$ of the protocols included adult subjects capable of giving informed consent.

Non-industry protocols more often received comments related to methodology and statistical analyses and the selection of participants than industry-sponsored protocols, while research based on published trials indicated that methodological quality was comparable for industrysponsored and non-industry trials [12-14]. RECs may play an important role in improving the quality of submitted protocols, which could explain the observed absence of substantial differences in methodological quality in relation to sponsorship among published trials. In contrast, industry-sponsored trials more often received comments on supporting documentation submitted alongside protocols. This difference seemed to be associated with REC comments on clauses in clinical trial agreements for industry-sponsored trials, in particular regarding the publication of results and premature termination of trials.

The time to protocol approval was comparable for non-industry and industry-sponsored trials, but was significantly different between RECs. Time to approval may be related to the quality and characteristics of submitted protocols, but may also reflect the efficiency of the review process. The REC in Nijmegen received lower proportions of industry-sponsored studies and trials with drugs not registered in The Netherlands. There may be other differences between submitted protocols that were not detected in this study. In Leiden and Amsterdam, protocols are reviewed by science committees before 
Table 3 Examples of REC comments on protocols of drug trials

Review criteria

1. Proportionality

2. Minimisation of risks $\&$ burdens

3. Privacy \& confidentiality

\section{Patient safety}

5. Recruitment process

6. Information sheet \& consent form

7. Subject selection

8. Protection vulnerable subjects

9. Methodology \& statistical analysis

10. Product information

\section{Supporting documentation}

12. Facilities $\&$ research staff

\section{Financial aspects}

\section{Example}

"The committee has serious doubts regarding the proportionality of the study, because the trial is very burdensome for participants and a number of potentially risky interventions are being combined".

"The committee would like to hear the expected benefit(s) of the study drug from the investigators; the clinical relevance of the trial is not clear".

"The committee wonders why it is necessary to burden patients with completion of the proposed quality of life questionnaires; much is already known about the quality of life of this group of patients".

"The investigators need to convince the committee of the usefulness of repeating skin biopsies and synovial biopsies".

"The committee notes that questionnaires should be stored coded; there should be no personal data on the questionnaires, as is the case now for a number of questionnaires".

"Trial medication is home delivered to participants by courier; the committee wants to know which provisions are made to prevent that participant addresses are known by the manufacturer".

"The committee wonders why no individual and group level stopping rules are defined and no DSMB is installed for this trial".

"The committee wonders whether it is possible, in view of patient safety, to sequentially include participants in this trial".

"The minimal time of $24 \mathrm{~h}$ to decide about participation is too short considering the chance of placebo treatment, and the potential risks and burdens of participating; it should be minimally 5 days".

"The committee is concerned whether enough patients can be included; this type of cancer is particularly seen in patients with metastases, but these patients cannot participate in the trial".

"The written subject information is too long and too difficult (regarding both vocabulary and style); the committee would like to see a completely rewritten version, understandable to a layperson".

"It should be more clearly explained to which extent the trial treatment deviates from the standard treatment and what subjects must undergo additionally by participating in the trial".

"The committee asks the investigators why they do not select subjects at inclusion based on pain complaints, while this is an objective of the trial".

"The committee has the impression that the exclusion criteria are not complete, considering the SPC text; in particular, the committee believes that children with heart disease or kidney failure should be excluded".

"The committee would like to hear substantive arguments for the need to include minors; the investigators have not justified why this group should be involved in this trial".

"The committee would like to hear how subjects and their relatives are informed on the procedures in case of resistance by subjects during the trial".

"The sample size calculation does not reflect the primary analysis described as a (mixed effect) repeated measures ANOVA; the current calculation does not reflect that there are 10 VAS pain measurements".

"The trial is designed as cross-over; because of potential carry-over effects, the committee believes that a parallel comparison of 2 groups should be preferred".

"The committee needs more information on the endothelin receptor antagonists; information on product characteristics, pharmacological characteristics, efficacy and safety, and pharmacokinetics is missing".

"The data in the IMPD are from 1997; the committee wants to know whether this batch is still being used or whether there has been a more recent production".

"The text in the Clinical Trial Agreement on (premature) termination of the trial and publication of results does not correspond to provisions in the Dutch regulation on assessment of Clinical Trial Agreements".

"The committee wants to know whether the sponsor takes responsibility for the clinical trial liability insurance for all participating centres".

"A student cannot be principal investigator for this trial, because a student lacks experience and cannot take final responsibility for the trial".

"The committee believes that, considering the treatment during the trial, an oncologist should be involved in the design and conduct of the trial".

"The committee would like to see an exact justification of the 100.000 euro that the department will receive for conducting the trial".

"The committee does not agree with the independent physician appointed for 3 of the participating centres; this person also works as a physician for the pharmaceutical company sponsoring this trial". 
Table 4 Analysis of REC comments - non-industry $(n=122)$ vs industry-sponsored trials $(n=104)$

\begin{tabular}{|c|c|c|c|}
\hline Review criteria & $\begin{array}{c}\text { Protocols with } \\
\text { comments, n (\%) }\end{array}$ & $\begin{array}{c}\text { Relative risk } \\
(95 \% \mathrm{Cl})^{*}\end{array}$ & P-value \\
\hline 1. Proportionality & $61(27.0)$ & & \\
\hline Non-industry & $34(27.9)$ & $0.95(0.62-1.45)$ & .805 \\
\hline Industry & $27(26.0)$ & & \\
\hline $\begin{array}{l}\text { 2. Minimisation of risks } \\
\& \text { burdens }\end{array}$ & $26(11.5)$ & & \\
\hline Non-industry & $15(12.3)$ & $0.92(0.44-1.91)$ & .820 \\
\hline Industry & $11(10.6)$ & & \\
\hline $\begin{array}{l}\text { 3. Privacy \& } \\
\text { confidentiality }\end{array}$ & $63(27.9)$ & & \\
\hline Non-industry & $29(23.8)$ & $0.93(0.65-1.34)$ & .695 \\
\hline Industry & $34(32.7)$ & & \\
\hline 4. Patient safety & $61(27.0)$ & & \\
\hline Non-industry & $36(29.5)$ & $1.31(0.84-2.04)$ & .228 \\
\hline Industry & $25(24.0)$ & & \\
\hline $\begin{array}{l}\text { 5. Recruitment } \\
\text { process }\end{array}$ & $47(20.8)$ & & \\
\hline Non-industry & $30(24.6)$ & $1.05(0.63-1.73)$ & .866 \\
\hline Industry & $17(16.3)$ & & \\
\hline $\begin{array}{l}\text { 6. Information sheet } \\
\& \text { consent form }\end{array}$ & $182(80.5)$ & & \\
\hline Non-industry & $100(82.0)$ & $1.04(0.94-1.13)$ & .468 \\
\hline Industry & $82(78.8)$ & & \\
\hline 7. Subject selection & $62(27.4)$ & & \\
\hline Non-industry & $44(36.1)$ & $1.58(1.01-2.47)$ & .045 \\
\hline Industry & $18(17.3)$ & & \\
\hline $\begin{array}{l}\text { 8. Protection } \\
\text { vulnerable subjects }\end{array}$ & $9(4.0)$ & & \\
\hline Non-industry & $6(4.9)$ & $1.53(0.38-6.07)$ & .549 \\
\hline Industry & $3(2.9)$ & & \\
\hline $\begin{array}{l}\text { 9. Methodology \& } \\
\text { statistical analysis }\end{array}$ & $160(70.8)$ & & \\
\hline Non-industry & $95(77.9)$ & $1.18(1.01-1.37)$ & .038 \\
\hline Industry & $65(62.5)$ & & \\
\hline 10. Product information & $65(28.8)$ & & \\
\hline Non-industry & $38(31.1)$ & $1.16(0.75-1.78)$ & .507 \\
\hline Industry & $27(26.0)$ & & \\
\hline $\begin{array}{l}\text { 11. Supporting } \\
\text { documentation }\end{array}$ & $154(68.1)$ & & \\
\hline Non-industry & $72(59.0)$ & $0.83(0.72-0.95)$ & .006 \\
\hline Industry & $82(78.8)$ & & \\
\hline $\begin{array}{l}\text { 12. Facilities \& } \\
\text { research staff }\end{array}$ & $57(25.2)$ & & \\
\hline Non-industry & $39(32.0)$ & $1.60(0.98-2.60)$ & .060 \\
\hline Industry & $18(17.3)$ & & \\
\hline
\end{tabular}

Table 4 Analysis of REC comments - non-industry $(n=122)$ vs industry-sponsored trials $(n=104)$ (Continued)

\begin{tabular}{llll}
\hline 13. Financial aspects & $39(17.3)$ & & \\
Non-industry & $25(20.5)$ & $1.65(0.90-3.01)$ & .103 \\
Industry & $14(13.5)$ & & \\
\hline
\end{tabular}

* Relative risks are controlled for the REC that reviewed the protocol.

submission to the REC, which may reduce the time needed by RECs to review methodological aspects. In addition, investigators submitting protocols to the REC in Leiden are invited to discuss their study with a preadvisor prior to REC meetings. In The Netherlands, RECs should complete reviews of drug trials within sixty days [18]. The clock stops when RECs ask questions to investigators, and restarts when the required information is provided. However, as time to approval consisted of time attributable to RECs and time used by researchers to respond to comments, no definite conclusions can be drawn.

Due to the retrospective design of this study, included protocols were already reviewed before RECs were asked to participate in this study and the behaviour of REC members was not influenced by awareness of an ongoing investigation. As we had unrestricted access to submitted protocols and correspondence between RECs and researchers, we were able to extract trial characteristics and REC comments without having to obtain permission from researchers or rely on a survey of researchers to obtain these data, excluding the introduction of response bias [23]. Although there was no response bias with respect to individual studies, there may be a response bias in terms of RECs if the committees that declined to take part somehow differed from participating committees. Nevertheless, by inclusion of protocols submitted to three RECs that are among the eight largest committees in The Netherlands regarding the number of studies annually reviewed, more than $20 \%$ of all drugs trials approved in The Netherlands in 2010-2011 were evaluated.

Many studies have focused on the methodological quality of published trials [12-14] or followed protocols approved by RECs until publication [23,24]. In contrast, we identified shortcomings of protocols based on REC comments raised prior to trial initiation. Quality assessments in previous studies may have been affected by incomplete reporting in published articles, as evaluations of the risk of bias in trials may have been confused with assessment of the adequacy of reporting [25]. REC comments may not inherently provide an objective reflection of the quality of submitted protocols, as it has been shown that REC review is variable regarding the decisions made on protocols [26-28]. Comments that are raised may be influenced by local variation in requirements, and may vary by REC even for the same protocol 
Table 5 Time to approval of submitted protocols

\begin{tabular}{lcc}
\hline & $\begin{array}{c}\text { Time to approval in } \\
\text { days, median (IQR) }\end{array}$ & P-value \\
\hline $\begin{array}{l}\text { Total protocols }(\mathbf{n}=\mathbf{2 2 6}) \\
\text { Sponsor type }\end{array}$ & $112(78-163)$ & .298 \\
Non-industry $(\mathrm{n}=122)$ & $101(75-158)$ & \\
Industry-sponsored $(\mathrm{n}=104)$ & $119(84-169)$ & .000 \\
REC & & \\
Nijmegen $(n=74)$ & $148(89-203)$ & \\
Amsterdam $(n=76)$ & $113(87-150)$ & \\
Leiden $(n=76)$ & $91(65-127)$ & .026 \\
Nijmegen vs Amsterdam & & .000 \\
Nijmegen vs Leiden & & .001 \\
Amsterdam vs Leiden & & \\
\hline
\end{tabular}

with multicenter trials $[28,29]$. In this study, the proportion of protocols that received comments varied by REC for most of the review criteria. It is difficult to determine whether this reflects variable protocol quality or variable review by RECs.

This study has certain limitations. First, we focused on protocols submitted to Dutch RECs. In addition to the variability found between RECs within the same country, ethical review processes also vary between countries $[30,31]$. This limits the generalizability of our findings to non-Dutch RECs, although $40 \%$ of the included trials were conducted in multiple countries. This study included trials that eventually received a favourable opinion. We did not evaluate protocols that were rejected by RECs. Although only 3\% of all trials annually reviewed in The Netherlands are rejected [17], it may be interesting to consider this group as the chance of rejection might be associated with sponsorship. However, this was beyond the scope of the current study.

In this explorative study, the categorization of REC comments was performed by one author, while this would ideally have been done by two or more independent assessors and disagreements resolved by consensus. The categorisation of REC comments may be considered as subjective. However, to our knowledge, this is the first study in which shortcomings of protocols of drug trials as identified by RECs have been compared by sponsor type. The internal and external validity of the classification checklist used in this study could be further verified in future studies with different assessors and different samples of research protocols submitted to RECs.

Finally, industry-sponsored and non-industry trials may not be similarly addressed by RECs. Pharmaceutical companies commonly perform large multinational trials, while non-industry trials are more often initiated and conducted by local investigators. In this study, 90\% of the industry-sponsored trials were multicenter studies, compared to $30 \%$ of the non-industry trials. RECs that are involved at a single site of a large multicenter trial might feel constrained in their ability to modify the trial design and limited in what changes they can make to informed consent forms. In addition, multinational industry trials may have already implemented comments from RECs in other countries before submission to Dutch RECs.

\section{Conclusions}

In conclusion, RECs identified important ethical and methodological shortcomings in protocols of both industrysponsored and non-industry drug trials. Investigators, especially of non-industry trials, should better prepare their research protocols in order to facilitate the ethical review process.

\section{Abbreviations \\ Cl: Confidence interval; IQR: Interquartile range; REC: Research ethics committee; RR: Relative risk.}

\section{Competing interests}

$\mathrm{MvL}$ reports no competing interests. $\mathrm{HJO}$ is a paid employee from Teva Pharmaceuticals. During the last 5 years, GAR only performed investigatorinitiated studies. For this research, GAR received grants from the Dutch Heart Foundation, Dutch Cancer Society and ZonMw and unrestricted grants from Pfizer, Boehringer-Ingelheim and Astra-Zeneca. He has participated in an advisory board organized by Novartis.

\section{Authors' contributions}

HJO originated the idea for this study together with MVL and the REC of the Radboud university medical centre. HJO, GAR and MvL were involved in the design of the study. MvL conducted the data analysis and wrote the first draft of the manuscript. GAR and HJO reviewed and revised the manuscript. All authors read and approved the final manuscript.

\section{Acknowledgements}

We thank the RECs of the Radboud university medical center (CMO), VU University Medical Centre (METc VUmc) and Leiden University Medical Centre (CME) for providing access to submitted protocols and correspondence with investigators. We thank Joanna IntHout (Radboud university medical center) for her statistical advice. We are grateful to Frits Lekkerkerker (chairman Dutch Association of Research Ethics Committees, NVMETC), Frans Huysmans (chairman REC Radboud university medical center), and Dyonne van Duren (director Clinical Research Center Nijmegen, Radboud university medical center) for reviewing and commenting on the content of this manuscript.

\section{Funding}

This research was supported by an unrestricted educational grant from MSD (Dutch subsidiary of Merck \& Co., Inc.). The funder had no role in the design and conduct of the study; collection, management, analysis, and interpretation of the data; preparation, review, or approval of the manuscript; and decision to submit the manuscript for publication.

\section{Author details}

${ }^{1}$ Clinical Research Centre Nijmegen, Department of Pharmacology Toxicology, Radboud University Medical Center, Nijmegen, The Netherlands. 2Department of Pharmacology - Toxicology, Radboud University Medical Center, Nijmegen, The Netherlands. ${ }^{3}$ Department of Internal Medicine, Radboud University Medical Center, Nijmegen, The Netherlands. ${ }^{4}$ Teva Pharmaceuticals, Amsterdam, The Netherlands.

Received: 19 August 2014 Accepted: 26 November 2014 Published: 10 December 2014 


\section{References}

1. Friedman L, Furberg C, DeMets D: Fundamentals of Clinical Trials. 4th edition. New York: Springer-Verlag New York Inc; 2010.

2. World Medical Association: Declaration of Helsinki - Ethical Principles for Medical Research Involving Human Subjects. Fortaleza: 2013.

3. Council for International Organizations of Medical Sciences (CIOMS) in collaboration with the World Health Organization (WHO): International Ethical Guidelines for Biomedical Research Involving Human Subjects. Geneva: 2002.

4. Emanuel EJ, Wendler D, Grady C: What makes clinical research ethical? JAMA 2000, 283(20):2701-2711.

5. Martin-Arribas MC, Rodriguez-Lozano I, Arias-Diaz J: Ethical review of research protocols: experience of a research ethics committee. Rev Esp Cardiol 2012, 65(6):525-529.

6. Bueno M, Brevidelli MM, Cocarelli T, Santos GM, Ferraz MA, Mion D Jr: Reasons for resubmission of research projects to the research ethics committee of a university hospital in Sao Paulo, Brazil. Clinics 2009, 64(9):831-836.

7. Kent G: Responses by four Local Research Ethics Committees to submitted proposals. J Med Ethics 1999, 25(3):274-277.

8. Angell $E$, Dixon-Woods M: Do research ethics committees identify process errors in applications for ethical approval? J Med Ethics 2009, 35(2):130-132.

9. Dixon-Woods M, Angell E, Tarrant C, Thomas A: What do research ethics committees say about applications to do cancer trials? Lancet Oncol 2008, 9(8):700-701.

10. Angell E, Biggs H, Gahleitner F, Dixon-Woods M: What do research ethics committees say about applications to conduct research involving children? Arch Dis Child 2010, 95(11):915-917.

11. Goldacre B: Bad Pharma. How Drug Companies Mislead Doctors and Harm Patients. 4th Estate, London: 2012.

12. Lundh A, Sismondo S, Lexchin J, Busuioc OA, Bero L: Industry sponsorship and research outcome. Cochrane Database Syst Rev 2012, 12:MR000033.

13. Schott G, Pachl H, Limbach U, Gundert-Remy U, Ludwig WD, Lieb K: The financing of drug trials by pharmaceutical companies and its consequences. Part 1: a qualitative, systematic review of the literature on possible influences on the findings, protocols, and quality of drug trials. Dtsch Arztebl Int 2010, 107(16):279-285.

14. Jones R, Younie S, Macallister A, Thornton J: A comparison of the scientific quality of publicly and privately funded randomized controlled drug trials. J Eval Clin Pract 2010, 16(6):1322-1325.

15. Damen $L$, van Agt F, de Boo T, Huysmans F: Terminating clinical trials without sufficient subjects. J Med Ethics 2012, 38(7):413-416.

16. Kasenda B, Von Elm E, You J, Blumle A, Tomonaga Y, Saccilotto R, Amstutz A, Bengough T, Meerpohl JJ, Stegert M, Tikkinen KA, Neumann I, Carrasco-Labra A, Faulhaber M, Mulla SM, Mertz D, Akl EA, Bassler D, Busse JW, Ferreira-Gonzalez I, Lamontagne F, Nordmann A, Gloy V, Raatz H, Moja L, Rosenthal R, Ebrahim S, Schandelmaier S, Xin S, Vandvik PO, et al: Prevalence, characteristics, and publication of discontinued randomized trials. JAMA 2014, 311(10):1045-1051.

17. Central Committee on Research Involving Human Subjects (CCMO): Annual Report 2011 Research Involving Human Subjects. The Hague: 2012.

18. Dutch Medical Research Involving Human Subjects Act (WMO). The Hague: 1998.

19. Directive 2001/20/EC of the European Parliament and of the Council - EU Directive Good Clinical Practice. Luxembourg: 2001.

20. International conference on harmonisation of technical requirements for registration of pharmaceuticals for human use: ICH Harmonised Tripartite Guideline - Guideline for Good Clinical Practice E6. 1996.

21. Central Committee on Research Involving Human Subjects (CCMO): Revised Directive on the Assessment of Clinical Trial Agreements. The Hague: 2011.

22. Stukart MJ, Olsthoorn-Heim ETM, van de Vathorst S, van der Heide A, Tromp K, de Klerk C: Second Evaluation Dutch Medical Research Involving Human Subjects Act (WMO). The Hague: ZonMw; 2012.

23. Redmond S, von Elm E, Blumle A, Gengler M, Gsponer T, Egger M: Cohort study of trials submitted to ethics committee identified discrepant reporting of outcomes in publications. J Clin Epidemio/ 2013, 66(12):1367-1375.

24. Blumle A, Antes G, Schumacher M, Just H, von Elm E: Clinical research projects at a German medical faculty: follow-up from ethical approval to publication and citation by others. J Med Ethics 2008, 34(9):e20.
25. Higgins JPT, Altman DG, Sterne JAC on behalf of the Cochrane Statistical Methods Group and the Cochrane Bias Methods Group: Chapter 8: Assessing Risk of Bias in Included Studies. In Cochrane Handbook for Systematic Reviews of Interventions. Version 5.1.0. The Cochrane Collaboration; 2011.

26. Abbott L, Grady C: A systematic review of the empirical literature evaluating IRBs: what we know and what we still need to learn. J Empir Res Hum Res Ethics 2011, 6(1):3-19.

27. Angell E, Sutton AJ, Windridge K, Dixon-Woods M: Consistency in decision making by research ethics committees: a controlled comparison. J Med Ethics 2006, 32(11):662-664.

28. Helfand BT, Mongiu AK, Roehrborn CG, Donnell RF, Bruskewitz R, Kaplan SA, Kusek JW, Coombs L, McVary KT, on behalf of the MIST investigators: Variation in institutional review board responses to a standard protocol for a multicenter randomized, controlled surgical trial. J Urol 2009, 181(6):2674-2679.

29. Stark AR, Tyson JE, Hibberd PL: Variation among institutional review boards in evaluating the design of a multicenter randomized trial. J Perinatol 2010, 30(3):163-169.

30. Goodyear-Smith F, Lobb B, Davies G, Nachson I, Seelau SM: International variation in ethics committee requirements: comparisons across five Westernised nations. BMC Med Ethics 2002, 3:E2.

31. Dovey S, Hall K, Makeham M, Rosser W, Kuzel A, Van Weel C, Esmail A, Phillips R: Seeking ethical approval for an international study in primary care patient safety. Br J Gen Pract 2011, 61(585):197-204.

\section{doi:10.1186/1472-6939-15-83}

Cite this article as: van Lent et al.: Shortcomings of protocols of drug trials in relation to sponsorship as identified by Research Ethics Committees: analysis of comments raised during ethical review. BMC Medical Ethics 2014 15:83.

\section{Submit your next manuscript to BioMed Central and take full advantage of:}

- Convenient online submission

- Thorough peer review

- No space constraints or color figure charges

- Immediate publication on acceptance

- Inclusion in PubMed, CAS, Scopus and Google Scholar

- Research which is freely available for redistribution

Submit your manuscript at www.biomedcentral.com/submit
C) Biomed Central 